\title{
Combating the destruction of Ethiopia's archaeological heritage
}

\author{
Asamerew Desie, Chester Cain, Niall Finneran, Michael Harlow \& Jacke Phildips*
}
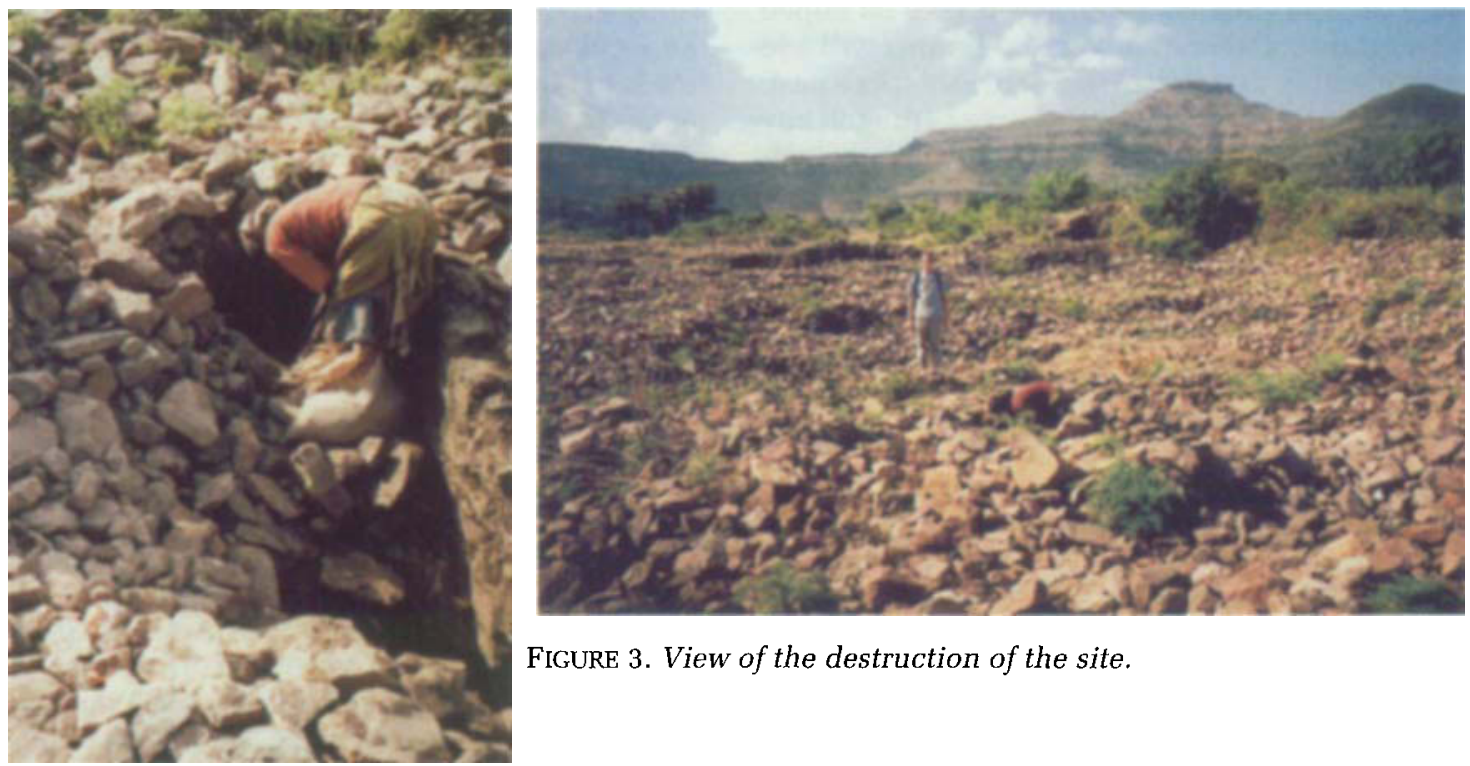

FIGURE 3. View of the destruction of the site.

FIGURE 2. Excavation of the archaeological deposit.

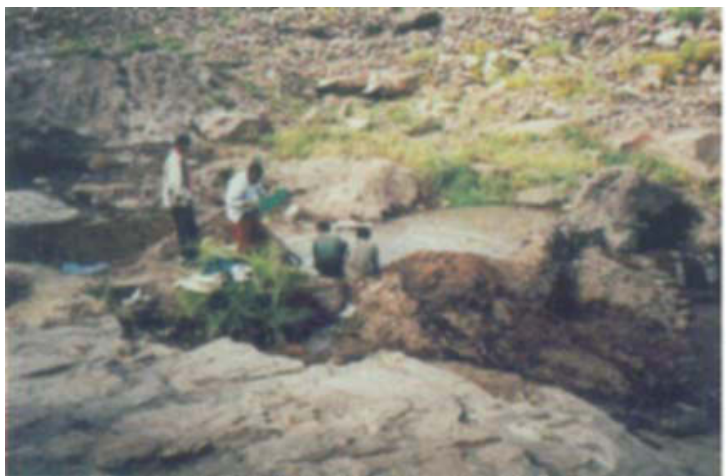

FIGURE 4. Panning the deposit.

During November 2001, a joint American-BritishEthiopian archaeological team under the direction of Niall Finneran undertook a multi-period archaeological landscape survey of the region of

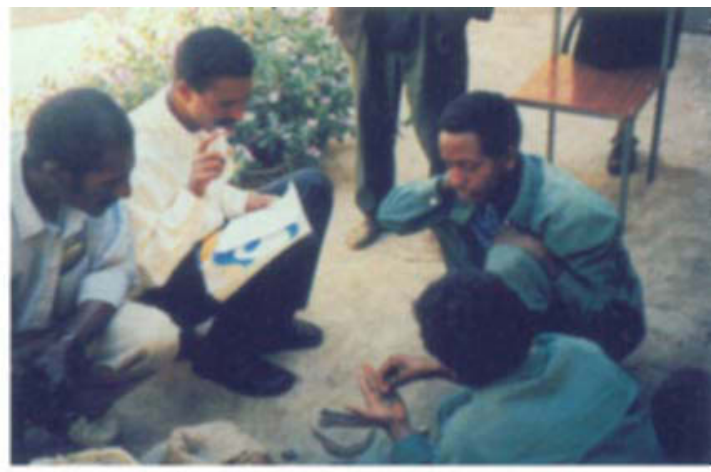

FIGURE 5. Processing finds at the Bureau of Culture, Inda Selassie.

Inda Selassie in the western administrative zone of Tigrai, northern Ethiopia (FIGURE 1, overleaf). Building on earlier work by the Ethiopian archaeologists Asamerew Desie and Tekle Hagos of the

* Asamerew, Authority for the Research \& Conservation of Cultural Heritage, PO Box 30795, Addis Ababa, Ethiopia. Cain, Department of Archaeology, University of the Witwatersrand, Johannesburg, South Africa. Finneran, Department of Archaeology, School of Oriental \& African Studies, University of London, Thornhaugh Street, London wC1H 0xG, England. Harlow, 35 Linwood Road, Bournemouth BH9 1DP, England, Phillips, McDonald Institute for Archaeological Research, University of Cambridge, Downing Street, Cambridge CB2 3ER, England. 
Authority for Research and Conservation of Cultural Heritage, Addis Ababa, a range of sites dating from the early stone age into the late medieval period were located. These data form the basis of a sites and monuments register for the Shire region around Inda Selassie, and it is to be hoped that future collaborative work in the area will add considerably to our knowledge of Ethiopia's past.

One of the key sites in this area is the tell site of May Adrasha. Large amounts of archaeological material have been noted eroding from this site over the last few years, but it has never been properly investigated. A cursory study of the ceramics by Jacke Phillips, and a more recent study by Chester Cain, have concluded that the lowest levels of this site may date from pre-Aksumite times, thus making it an early indicator of urbanism and socio-cultural complexity on the high Ethiopian plateau. During a visit to the site in December 2000, Michael Harlow noted that local peasants were digging holes in the site and removing the spoil to pan for gold (of a non-archaeological variety, see FIGURE 2 ).

In the intervening time, and especially over the long Summer Belg rains, this activity has unfortunately grown considerably, and the scale of destruction is potentially devastating. Now perhaps $40 \%$ of the site has been damaged by illicit digging (FIGURE 3 ); the spoil is removed and panned in the nearby river (FIGURE 4). Virtually all ar-

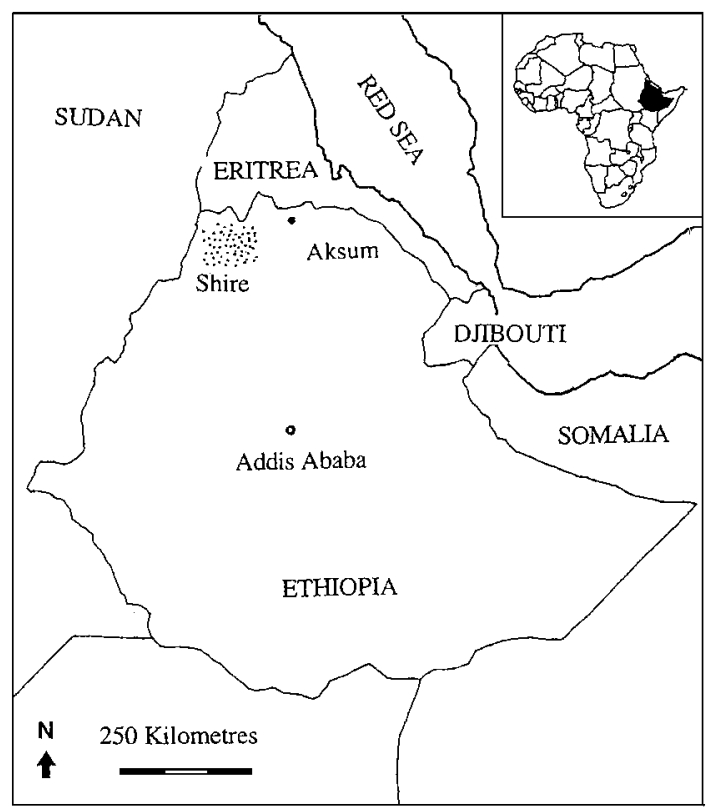

FIGURE 1. Location of the survey region within Ethiopia. chaeological material is removed and dumped, and on the rare occasions natural gold is found it is usually sold on through two dealers in the town at a going rate of Birr 70 per gramme (about $£ 6$ ). Occasionally some of the more obviously interesting archaeological material makes its way to the local culture bureau, where the usual practice is to offer a token reward for it being handed in. On the last day of our survey a large amount of pottery, glass, metal work, beads, coinage and human figurines arrived at the bureau where they were rapidly catalogued and photographed by the team (FIGURE 5).

This is an unsatisfactory situation; the site demands controlled archaeological excavation and high-grade protection. In conjunction with our Ethiopian colleagues, the local town council (Woreda) was notified, and using no more than word of mouth, the site was immediately put off limits to all. We have also requested adequate signage and secure fencing to be erected around the site - the latter course of action has been successfully used at Aksum to protect the Gudit Stelae Field. The costs for this work cannot be realistically expected to be met from local sources, and it would be desirable for the wider Ethiopianist archaeological community to make a contribution, be it financial or practical (i.e. the provision of conservators and dedicated storage facilities for the finds already at the town library). The latest legal framework for the protection of archaeological sites in Ethiopia, Proclamation 209, June $2000,{ }^{1}$ makes the subject clear. Severe fines, and in some cases prison sentences, may be levied upon persons destroying archaeological sites (section 45, paragraph 2). It is hoped that this brief contribution alerts the international archaeological community to the damage that is being done to an intriguing site, and may help stimulate the planning and execution of a concerted salvage excavation on a site that is not just important in the Ethiopian context, but also potentially on the wider African stage.

1 Source: Federal Negarit Gazeta of the Federal Democratic Republic of Ethiopia $6^{\text {th }}$ Year No. 39. Addis Ababa, 27 June 2000.

Acknowledgements. Fieldwork was supported by grants from the British Institute in Eastern Africa, the Society of Antiquaries of London, the central research fund of the School of Oriental \& African Studies, University of London, and the British Academy. The team wishes to record its gratitude to the federal, regional and local Ethiopian antiquities staff. This contribution is respectfully dedicated to the memory of our former Ethiopian colleague Ato Gebrekidane Woldehariat, whose work laid the foundations of this present project. 